\title{
Linguistic Interference from Hindi in Indian English
}

\author{
Shalini Mishra \\ Research Scholar, Linguistic Department \\ Lucknow University Lucknow, U.P. India \\ shalinikit@gmail.com
}

\author{
Dr. Anjani Mishra \\ Former Assistant Professor \\ MSIT, New Delhi, India \\ amishra_76@yahoo.com
}

\begin{abstract}
English is one of the three largest spoken human languages of the world. Though it is not mentioned in the $8^{\text {th }}$ schedule of the constitution of India, yet it is widely used in India. Due to influence of the major languages of India, now it is developing as an Indian language i.e. Indian English. 'Indian English', compact phrase, refers to various forms of English used in different states of India. Several renowned scholars dealt with the term 'Indianisation' of English on the basis of the data provided from earlier Indian English Writings. The present paper presents a very brief introductory history of English along with its growth and function in the country of diverse languages with the ultimate aim to describe linguistic interference from Hindi in English at various levels of linguistics; so that Indianness in Indian English can be stated as the chief characteristic of one of the growing variety of English. It may also be helpful in determining the scope of this variety of English.
\end{abstract}

Keywords: Historical background, linguistic interference, reasons, types.

\section{INTRODUCTION}

In Indian context 'Linguistic Interference from Hindi in Indian English' is an acute requirement of time for the growth and development of English Language. It must not be considered as a mistake or an error because most of the time it is an intentional activity for some very specific reasons; like trading, communication, establishing friendly relation, to impress (Indians and others), to govern etc.

"On 31 December 1600, Queen Elizabeth signed a Charter granting permission to a group of enterprising merchants of the city of London to trade with India...." This has initiated linguistic interference from Indian languages to English and vice versa. The merchants of the trading body, the East India Company, were known as "Indian Nabobs" in England whereas "The EIC remained only "jageerdars" under the Mughal Sovereign till 1759. These frequently used Indian titles and other words by the British themselves, during the exploration and transportation phase, gave way to the linguistic interference from Hindi, Urdu and other Indian languages into English. Later on, this practice was full heartedly adopted also by Indians and other English speakers. This linguistic interference can also be observed in official and judicial activities. The Act of 1765 was named as 'Diwani Act' (by which the EIC collected the revenue as 'Diwan' in Indian regions like Bengal, Bihar and Orissa). The terms 'Diwani' also indicates the impact of Hindi grammar on English language because the term 'Diwan' means 'Collector', (one who collects) and by adding Hindi suffix ' $-i$ ' to it, it communicates 'that is related to collection' or 'something related to collection'. Hence 'the Diwani Act' means 'the Act related to the collection of revenue'. The names of the institutions founded by Warren Hastings, the Governor (1772 to 1785) may also be taken as examples of Linguistic interference, for one was 'Calcutta Madrassa' (founded in 1781) and another was 'Banares Sanskrit College' (founded in 1791). The words 'Madarsa' and 'Sanskrit' both are from Indian languages and both represent Indianness. In present scenario such interferences, sometimes, are full hearted accepted; even sometimes users as well as listeners remain so unaware to notice the occurrence of any such interference. At lexical level, this interference, from Hindi and some other Indian languages, has also been adopted by most renowned English dictionaries. This caused the inclusion of several Indian words (especially Hindi words) in English language. Though, interference is an obvious process during social contact between two groups of different languages. Even bilinguals, often, serve "as the agent of diffusion"1 ${ }^{1}$ (that takes place purely in spoken form).

\footnotetext{
${ }^{1}$ Southworth, Franklin C. 2004. Linguistic Archaeology of South Asia. Routledge. P.16.
} 


\section{MAJOR REASONS OF LINGUISTIC INTERFERENCE}

The term 'linguistic interference' (introduced by Uriel Weinreich) "denotes the process of deviation from the structural norms of a language manifested in the speech of bilingual persons as the result of their familiarity with another language." Some major reasons that cause linguistic interference are follows:

2.1. More exposure case in Mother tongue / First language than second or foreign language.

2.2. Learning of mother tongue or first language occurs naturally. It is generally related to functional grammar; i.e. for understanding and following grammatical rules, no direct efforts are made whereas to learn or acquire second or foreign language, one has to follow strict grammar rules. This often causes overlapping and linguistic interference.

2.3. Vocabulary of second and foreign language is generally very limited; hence interference from mother tongue or first language becomes an acute need for an exact expression \& communication.

2.4. As none can refrain oneself from the impact of mother tongue, thus, the Indians who teach Standard English cause interference from Indian languages (especially in pronunciation and grammar).

2.5. Sometimes linguistic interference occurs to show one's expertise on more than one language.

2.6. When the second or the foreign language becomes handicap to present any cultural, regional, religious or traditional meaning or context of the first language or the mother tongue, one has to let interference occur.

2.7. Several times, for the sake of promoting curiosity and novelty, interference is skillfully taken into use.

\section{TYPES OF LINGUISTIC INTERFERENCE FROM HINDI IN INDIAN ENGLISH}

On the basis of the aforesaid reasons, linguistic interference can be distinguished into following six types:

3.1. Phonetic / Phonological Interference ( Related to Pronunciation)

3.2. Grammatical / Structural Interference

3.3. Lexical / Vocabulary Interference

3.4. Idiomatic Interference

3.5. Contextual Interference

3.6. Spelling Interference

\subsection{Phonetic/ Phonological Interference (from Hindi into English)}

"Phonological interference is the strongest and, perhaps, hardest to avoid." ${ }^{2}$ In this Hindi, sounds, stress, rhythm, pitch and intonation pattern interfere into English language. These interferences occur because some sounds; like $/ \mathrm{D} /, / 3 /$ etc. do not exist in Hindi. Hence, a habitual Hindi speaker, knowingly or sometimes unknowingly, interferes some similar sound to pronounce them. Some other phonemes are also articulated differently; e.g.

a) "Father! Ramdayal, the doorkeeper, calls a crow a krow!" (The Cabuliwallah, 5)

b) "It's not PIJJA. It's Pizza.... There's a T in the middle. Peet Zah.... Pijja, Pzijja, Zippja, Pizja..."

(The White Tiger, 154)

These examples show the difference as well as problems in the articulation of some English sounds in the English manner. Many a times, Indian English speakers are not familiar with the rules of English pronunciation. There are differences between the rules of Hindi and English pronunciation.

- Due to interference of Hindi, deletion of sound / $r$ / does not occur in any word position in the speech of most of the Indian English speakers; whereas in Standard British English sound / $\mathrm{r} /$ occurs only before a vowel; e.g.

\footnotetext{
${ }^{2}$ Tiwari, Saket Raman. 2010. Teaching of English. New Delhi: APH Publishing Corporation. P.144.
} 


\begin{tabular}{|c|c|c|c|}
\hline $\begin{array}{l}\text { English } \\
\text { Words }\end{array}$ & $\begin{array}{l}\text { Standard British Pronunciation } \\
\text { (http://dictionary.cambridge.org/ } \\
\text { dictionary/british/) }\end{array}$ & $\begin{array}{l}\text { American Pronunciati } \\
\text { (http://www.merriam- } \\
\text { webster.com/dictionary) }\end{array}$ & $\begin{array}{l}\text { Interference of Hindi Pronunciation } \\
\text { system }\end{array}$ \\
\hline Conserve & /kən's3:v/ & ไkən-'sərv〉 & /kən'sз:rv/ or /kən'sə:rv/ \\
\hline Pearl & /p3:1/ & \'pər(-ə)l\ & /p3:rl/ or /po:rl/ \\
\hline Shirt & $/ \sqrt{3}: \mathrm{t} /$ & \'shərt \} $&{\text { //3:rt/ or / } \int ə: r t /} \\
$\hline
\end{tabular}

- Because of the interference of Hindi phonemes, in the speech of many North Indians instead of sound / 3 / only /ə/ occurs; (Bansal: The Intelligibility,121); e.g.

\begin{tabular}{|l|l|l|l|}
\hline English Word & British Pronunciation & American Pronunciation & Interference of Hindi Pronunciation system \\
\hline Girl & gз:1/ & ' 'gər(-ə)1 & /g3:rl/ or /gə:rl/ \\
\hline
\end{tabular}

- Interference from Hindi speech system does not permit any of the aspirated sounds; whereas it always occur in Standard English in the production of / p /, / t / and / k / at initial state of syllable and word.

- Interference from Hindi also causes flat pronunciation even of a stressed syllable or putting stress on an unstressed syllable. Stress and intonation are of extreme importance in Standard English but has no major relevance in Hindi word syllable because Hindi (most of the other Indian languages) has not such type of rule to distinguish the parts of speech. That is why most of the Indians cannot make differentiation in a verb and noun; e.g. 'Import $=$ Noun and Im'port $=$ Verb

- Epenthetic vowels / I, ə / often proceed the clusters / sp, st, sk /; e.g.

\begin{tabular}{|l|l|l|}
\hline Word & Standard English & Interference from Hindi \\
\hline Spring & /sprın/ & /Isprın/ \\
Spoon & /spu:n/ & /Ispu:n/ \\
Spiral & /'spaə.rəl/ & /I'spaə.rəl/ \\
School & /sku:l/ & /Isku:l/ \\
Stool & /stu:l/ & /Istu:l/ \\
\hline
\end{tabular}

- The sound of /I/ is inferred Indian English in the words that begin with two or more consonant sounds. In English language such words don't have vowel between them. English language has a number of such words but in Hindi, words do not begin with these consonant sounds especially without a vowel sound. This is the reason why Indians infer vowel /I/ at the beginning of such words.

- From Hindi speech system, the aspirated voiceless dental plosive / th / is interfered for / $\theta /$ of Received Pronunciation; and / d /, the unaspirated voiced dental plosive, interferes for / ð / of Received Pronunciation.

- Interference from Hindi also gives way for the retroflex plosives / T / and / D / replacing the alveolar plosive of Standard English / $\mathrm{t} /$ and / d /.

- In English language there is "no one to one correlation between spelling and pronunciation"” whereas almost every Indian language is phonetic. Every letter of alphabets of Indian languages denotes sound which is generally same in their spoken and written form. Similarly, Hindi matches the spoken form with the written form where as Roman languages often lack such quality. This causes English silent sounds to be pronounced by most of the Indian speakers (if not trained); e.g. in Standard English 'bridge' is pronounced leaving / $\mathrm{d} /$ sound as /bridz/; which is often pronounced using / d / sound in Indian English.

\subsection{Structural or Grammatical Interference}

\subsubsection{Use of Intonation to form an Interrogative from an Affirmative Structure}

Because of structural or grammatical interference from Hindi language, Hindi sentence structure is generally used in an English sentence; especially while making an interrogation. In Hindi, question is also being asked by the use of intonation on an affirmative structure. Such types of structure are often heard in oral Hindi communications. e.g.

\footnotetext{
${ }^{3}$ Radika, V. and Kala Mary Surya. April, 2013. Interference of Mother Tongue in Learning a Foreign Tongue. ELT Voices - India. Vol. 3. Issue-2. P. 99.
} 
- You are going? instead of 'Are you going?'

- 'Good, you came, Chitralekha? (Urvashi, 83) (Achha, tum aagayee Chitralekha ?) instead of 'Good, did you come Chitralekha?' (Achha, kya tum aagayee Chitralekha?)

\subsubsection{Repetition used for Emphasis and over Emphasis}

Most of the Indian Languages, including Hindi prefer emphasis, sometimes overemphasis. Repetition is one of the Indian devices used for the purpose; e.g.

\section{(Repetition of Noun)}

i) 'There are only lotus, and lotus...' (Urvashi, 41) (wahan par keval kamal hi kamal hai)

Standard English: There are only lotuses.

ii) From house to house, house to house, house to house (The White Tiger, 60) (Ek makan se dusre makan) Standard English: From one house to another.

\section{(Repetition of address)}

i) "Babuji, Babuji, God will make you prosperous". (Untouchable, Anand, 90)

Standard English: May you be prosperous! OR May God make you prosperous!

\section{(Repetition of Main Verb)}

i) 'I am getting burnt-burnt....'(Urvashi, 107) (Mai jalija rahe hu)

Standard English: I am getting burnt.

i) I got, got (Urvashi, 125) (Maine pa liya, pa liya) Standard English: I got.

\section{(Repetition of Helping Verb)}

i) I don't smoke, I don't drink, I don't steel.....I don't disrespect God, I don't disrespect my family.... (The White Tiger) Repetition of don't

Standard English: I neither smoke nor drink nor steel.... I neither disrespect God nor my family.

\section{(Repetition of Present Participle)}

i) That sparkling - sparkling spring of water. (Urvashi, 97) (Wah jhar-jharata hua pani ka jharna) Standard English: That sparking spring of water.

The above quoted extracts give a clear picture of repetition at various parts of speech for emphasis or over emphasis. This presents the linguistic interference from Hindi and internal analogy in the Grammar of Indian English.

\subsubsection{Unnecessary Deletion or Insertion of Any Part of Speech on the Analogy of Hindi Grammar}

In Indian English sometimes, some words are unnecessary inserted or deleted e.g.

i) "I do not have anything." (Urvashi, 40) (Mere pass kuch nahi hai)

Standard English: I have nothing.

ii) "Only a short time before...." (The Child's Return, Tagore, 49)

Standard English: Only a little time before...

iii)When Gaffur's car did turn up. (The Guide, P.86) Use of helping verb 'did' in Affirmative sentence.

Standard English: When Gaffur's car turned up.

iv) 'You were so interested and carefree and happy then.' (The Guide, P.131) Unnecessary use of 'and' instead of 'a comma'

Standard English: You were so interested, carefree and happy then.

v) 'Why stand there?' (The Guide, 140) Deletion of helping verb and pronoun

Standard English: Why do you stand there? 
vi) 'Did you or did you not promise that you would never mention it again? (The Guide, 148) 'use of did'

Unusual use of 'did' as 'Did you or did you not promise...' based on the analogy of Hindi grammar as 'Tumne wada kiya tha ya nai...'

vii) Not only does he have to have perfect relax... (The White Tiger, 215) Unusual use of verb

viii) Do you know what $99 \%$ doctors have used when in pain? (Stardust, Dec. 2012. Issue, P. 33) Standard English: Do you know what $99 \%$ doctors use when they feel pain?

OR Do you know what $99 \%$ doctors use in/during pain?

\subsubsection{Use of Interrogative word as an Interjection}

"Why! What will happen tomorrow?" (Urvashi, 94) (Kyo kal kya hoga?) Based on Hindi Grammar

\subsubsection{Virtue conjugated with vice}

"A fat and fair boy" (A Dying Banyan, 29)

\subsubsection{Use of Hindi Suffix ' $-i$ '}

“Abbu's Muradabadi brass spittoon” (A Dying Banyan, 23) (Interference of Hindi 'case of possession' instead of (-'s) apostrophe or preposition 'of' and preposition 'of')

Standard English: Abbu's spittoon of / made of brass from Muradabad.

\subsection{Lexical Interference/Vocabulary Interference}

Lexical interference or vocabulary interference from Hindi into English language occurs in the following ways:-

\subsubsection{Direct Lexical Interference (code switching)}

In this type of interference a term or word from Hindi-Urdu or any other Indian language occurs into English without any change or modification e.g.

- "Kiss my chuddies" (The Observer, April, 2004) (Hindi word chuddi (चूड़ी) is taken in inflected form and used as English plural (-ies).

- "Life isn't all Ha Ha Hee Hee" (Name of the famous BBC TV programme: Hindi words ' $\mathrm{Ha} \mathrm{Ha}$ Hee Hee' refers to laughter or pleasant times)

- "After she had re-turned it, the Ustad sang a few phrases of a slow alaap..." (A Suitable Boy, 294) The urdu word 'Ustad' for master and Hindi word 'alaap' for musical notes have been used as it is).

For this kind of interference (Direct Lexicon) thousands of examples can be cited from various sources. Native as well as non-native writers, poets, journalists as well as the common users, all use Hindi lexicon as per their need and desire. 'Light of Asia' by Sir Edwin Arnold (1832) also encounters several lexicons of various registers from Hindi language. Some are as follows:

- Culture - Purdhah

- Religion - Swastika, Tilak

- Mythology - Yakshas

- Numeric - Lakh

- Spirituality - Dhyana, Guru, Achrya

- Flora \& Fauna - Tulsi, Asoka, Jumbu Tree, Nelumbo, Karunda, Mogra, Koil, Bulb

- Cosmetics - Soorma-stick

- Superstitions - Bhut

- Insect \& Reptiles - Nag (used for a reptile)

- Casticism - Ksatriya, Sudra 
- Architectural - Angana, Koss

- Weighing unit - Tola

- Musical instrument - Sitar

- Transportation - Gadi

- Planning - Yojana

- Indian Rituals - Jama kand, Karma kand

- Seasons - Wasant

- Castes- "The Brahmin proud, the martial Kshatriya, the humble toiling Shudra..." and many more.

Similarly, the writings of Indian writers in English are full of Hindi words because of the requirement. Bhattacharya, Raja Rao, Rohinton Mistry, Adig, Jhumpa Lehri, Vekram Seth, Khushwant Singh, Shashi Taroor etc. are among them. Many a times, when no word of English seems that much eligible to fulfill the requirement, interference of Hindi lexicon becomes an acute requirement.

\subsubsection{Translated Interference}

In this type of interference a Hindi word or term is directly or plainly translated into English whereas the translated term is not in that type of use in Standard English e.g.

- "cow dust hour" (The Strange Case of Billy Biswas, 99) for ' gau dhuli bela'

- "song writer uncle" (Ibid, 64) for 'geetkaar chacha'

- "incense stick" (The White Tiger, 165) for 'dhoop/agar batti'

- "lotus position" (Ibid, 195) for 'padamaasan' (This term belongs to Indian Yoga Shastra.

Since Indian 'Yog' (Yoga) has been internationally recognized, most of the Hindi / Sanskrit related terms have also been acknowledged and adopted internationally.

\subsubsection{Partial Lexicon Interference}

In this, either of an item of a compound term, interferes from Hindi language e.g.;

i) Hindi Word+ English Word

- Toupee job $=$ Toupee + job for 'Toupee kaam' (The White Tiger, 226)

- Tandav dance $=$ Tandav + dance $($ Stardust Dec. 2012,39$)$

- Sehri Time $=$ Sehri+time $($ TOI, 28/12/12)

- Heena design $=$ Heena + design $($ The Sari Shop, eBook $)$

- Mehndi ceremony $=$ Mehndi + ceremony $($ Ibid $)$

- Vilayati blood = Vilayati + blood (The Strange Case of Billy Biswas, 114)

ii) Hindi Word+ English Word

- Bridal odhnis $=$ Bridal + odhnis $($ The Sari Shop, eBook)

- Ivory chooda $=$ Ivory + chooda $($ Ibid $)$

- Expensive kaleere $=$ Expensive + kaleere $($ Ibid $)$

- Potato vada $=$ Potato + vada for "Aalo vada (The White Tiger, 20)

- Major Sahib = Major + Sahib (Coolie)

iii)English word + Hindi Suffix

- Bioscopewalli $=$ Bioscope + wali (Stardust, Dec. 2012)

- Boxwala $=$ Box + wala for 'Dubbe wala' (India: A Million Mutinies Now) 
3.3.4. Interference of Hindi Lexicon with English Grammatical Influence or Vice Versa.

- 'Brahminical' (India: A Million Mutinies Now P. 246) \& 'Brahmanic' (Kanthapura, 3) Hindi word 'Brahmin' (Common Noun) is grammatically modified as 'Brahminical' and 'Brahmanic' to be used as adjectives.

- 'daily passengeri' (The Hungry Tide, 4) 'Passenger' is an English noun word but the use of Hindi suffix '-i' makes it an adjective

- 'Maaroing chakkars' (Stardust, Dec. 2012) means 'repeatedly visiting somewhere' or 'hovering around'. Hindi words 'maaro' and 'chakkar' are taken in their transliterated form but have influence of English grammar; e.g. 'maaroing' = maaro+ing (Present Participle form of English Grammar), and 'chakkars' = Noun Plural number of English Grammar.

\subsection{Idiomatic Interference}

There is not correspondence between the two languages (Hindi and English) on articles and prepositions. Hence, whenever articles, propositions or any other parts of speech lapse or unusually appear due to influence of any Indian language (Hindi), "idiomatic interference" language. In Indian English, several times, prepositions are not used in the way as they are used in Standard English; e.g.

- "Chandu was my senior by about six month... (The Barber's Trade Union, 7) Use of 'by about' is an interference from Hindi (Mujhse lagbhag)

- I discussed about the movie Titanic. (मैंने टाइटैनिक मूवी के बारे में विचार विमर्श किया) In this statement preposition 'about' is used on the analogy of 'talked about'. (According to Standard English 'about' is not required in this sentence.)

In Indian English, due to interference from Hindi language and internal analogy of grammar, prepositions generally occur in the following three ways, this also causes interference from Hindi:

i) Prepositions are lapsed where required.

ii) Prepositions are used where not required.

iii)Prepositions are used in an inappropriate manner.

In Hindi language, articles have no existence in any form. Articles are the "source of great difference between registers of Indian English and register of other varieties of English." 5 This is just because the interference from Hindi and its grammar. As in Hindi language, articles do not exist, thus the interference of Hindi causes the following three situations for Indian English:

i) Use / absence of articles before ordinal numbers; e.g. Gandhi ji was born on second October.

ii) Absence of article in noun phrases; e.g. I can tell number of ways to do this.

iii) The use / absence of articles in the quantifiers e.g. little, a little, the little, few, a few, the few, a number of etc.

Other than this, use/ absence of articles can also be traced in Indian English at various other places due to interference of Indian languages; e.g.

- “One is must. Boy girl. Anyone." (The Gods of Small Things, 130)

Standard English: One is must. Either it is a boy or a girl.

- "He is genius." (Ibid, 274)

Standard English: He is a genius.

- "Design is same. Only difference is in text, I suppose." (Ibid, 276)

Standard English: The design is same. The only difference is in the text, I suppose."

\footnotetext{
${ }^{4}$ Tiwari, Saket Raman. 2010. Teaching of English. New Delhi: APH Publishing Corporation. P. 144.

${ }^{5}$ Balasubramanian, Chandrika. 2009. Register Variation in Indian English. U.S.A.: John Benjamins Publishing Company. P.76.
} 
- "He is good worker." (277)

Standard English: He is a good worker.

- "Of course, inside the house she is boss." (278)

Standard English: Of course, inside the house she is a boss.

\subsection{Contextual Interference}

Contextual interference is also an outcome or consequence of direct translation. As in Hindi and in Indian culture several aspects are different from that of English, hence, contextual interference occurs; e.g.

- "touching feet" (The Namesake, 37)

- “...bow down to touch his feet, and touch the dust under his slippers" (the White Tiger, 25)

The above mentioned Indian gestures are not time bound (Though, up to certain extent, it is age, relation, caste or status bound); whereas, bidding 'good morning' would be contextually wrong; if meeting a person other than the morning. Similarly, bidding someone 'good night' while meeting during morning, noon, afternoon or evening will also be contextually wrong because the bidding phrase 'good night' is a term to be used or wished while parting at night only.

As there are no such complications in common / general Hindi communication, people don't hesitate to interfere context from Hindi and as a result a number of persons (esp. students) may be found bidding 'morning' even during afternoon and evening.

\subsection{Spelling Interference}

Along with other type of interference from Hindi language, spelling interference has also been occurring since the very beginning and continuing till now. It is also expected that it will flourish day by day. Hindi is one of the languages that have no variation in sound and symbols. In Hindi, if there is any variation in sounds and symbols (if argued), it is always based on set rules; e.g. 'बहन'it is often pronounced as 'बहिन' and 'बैहन'. (These rules may be studied under the headings 'sandhi aur samas' in Hindi and Sanskrit grammar.)

Sometimes, even in English language, due to interference from Hindi (Pronunciation and spelling system), variations occur at spelling level. It cannot be considered as mistake because for several words American spellings are accepted then why not Indian. Though, Indian writers and speakers follow spellings of both, Standard English and American English, yet for almost every Indian item and term, they have to create their own spellings; e.g. For Indian words: -

- Proper nouns - 'Iqbal', Khushwant'

- Honorific Tag - 'Sahib', 'Huzoor'

- Suffix - -ji, -sahib, etc.

- Address or rank - 'Babu' etc.

- Relations - 'Chacha', 'Bua' etc.

- Blessings \& prayers - 'Sat Sri Akal', 'Ram-Ram' etc.

- Complimenting words - 'Haseen'

- Exclamatory words - 'Chal! Chal'

- Relation - 'Bhaiji'

- Cultural word - 'Sanskar', 'satvik'

- Abusive words - 'Sala'

- Flora-fauna - 'Tulsi', 'Neem' etc. 
- Others - 'Aahimsa', 'Sanskar' etc

All these words from Hindi are being written in transliterated form in English spellings. All are spelt as they are pronounced. This is because of the interference of Hindi tendency. This causes no confusion even to a new user as it is hundred percent based on the patterns of pronunciation. Because of this, most of the traditionally accepted spellings of Standard English have given place to American spellings. American spellings are more corresponding to their pronunciation. Hence, Hindi spelling and pronunciation system seems closer to that of Americans.

In spite of being closer to the spelling system corresponding to the pronunciation, Indian English users face certain problems. Though, they try their best to form spellings exactly similar to the pronunciation yet due to lack of certain sounds in English language they have to prefer any nearly similar spelling based on pronunciation. This is so because certain Hindi sounds have no equivalent letter in English alphabet; e.g. < cha > for च, छ; <n > for F, ण, न; <t > for ट, त; < d > for ड, द; < $\mathrm{dh}>$ for $ढ, ~ ध$ etc. It should also be noticed that in the production of single sound 'च' or 'छ' three letters from English alphabet have to be taken. Thus, confusion prevails for Indian users. Hence, they wonder whether 'Chal' is 'चल' (to walk [verb], unstable [Adj.]) or 'छल्ल' (deceit [noun, verb])

Sometimes, innovative changes in spellings have also been marked in available English words. This was again due to the interference from Hindi. To provide a complete dialectical Indian touch, some great Indian authors and writers provided innovative spellings; e.g.

1) 'injan' (Coolie, P7) for 'engine'

2) 'sangscrit' (A letter, Raja Ram Mohan Roy to Lord Amherstin, Dec. 1823) Now a days, it is spelt as 'sanskrit' instead of 'sangscrit'

3) 'Muhammadans' for 'Mohammads' (From Indian writings in English: Critical Explorations, Jaydeep Sarangi, 56) etc.

Hence, it can be said that linguistic interference of Hindi in Indian English is an unavoidable feature. It is a result of language contact. Several times it occurs automatically whereas sometimes it is intentionally done. Linguistic interference of Hindi in English language, used in Indian contexts and situations, performs the same purposes of communication that any Indian language serves. Though, it is somehow deviated from the Standard varieties yet it is the best medium to describe Indian thoughts and things in the very Indian way. In the absence of linguistic interference from Indian languages, several Indian descriptions given in English will be stereotype and mechanical.

\section{REFERENCES}

[1] Balasubramanian, Chandrika. 2009. Register Variation in Indian English. Amsterdam: John Benjamins Publishing Company.

[2] Braj B. 1983. The Indianization of English: The English Language in India. New York: Oxford University Press.

[3] Krishnaswami, N. and Lalitha. 2006. The Story of English in India. New Delhi: Foundation Books Pvt. Ltd

[4] Mishra, Krishna Chandra. 2005. Correction of Errors in English: A Training Course. New Delhi: Swarup \& Sons.

[5] Radika, V. and Kala Mary Surya. April, 2013. Interference of Mother Tongue in Learning a Foreign Tongue. ELT Voices - India. Vol. 3. Issue-2.

[6] Southworth, Franklin C. 2004. Linguistic Archaeology of South Asia. Routledge.

[7] Tiwari, Saket Raman. 2010. Teaching of English. New Delhi: APH Publishing Corporation. 


\section{AUTHORS' BIOGRAPHY}

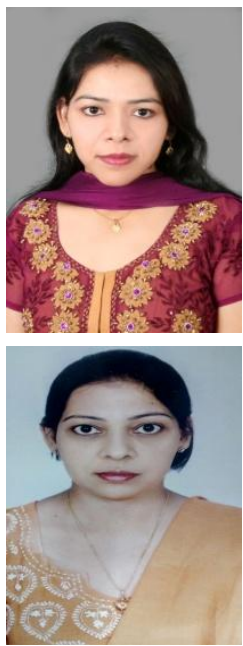

Ms. Shalini Mishra is pursuing Ph. D. in Linguistics from Lucknow University, Lucknow. The topic of her research is 'Indianization of English: A Descriptive Study of Indian English. She has a keen interest in the socio-linguistic aspects of Hindi and English language.

Dr. Anjani Mishra, former Assistant Professor, MSIT, New Delhi has done her research in English Literature from CSJMU, Kanpur. The topic her research was 'Existential Strain in the Poetry of Robert Frost.' She had served in several renowned institutes of the country. She has also been a devoted learner of AngloIndian Literature. The area of her interest consists of poetry and fiction. 